between research and teaching at the higher levels. To the solution of these problems the universities, the technical colleges and industry itself, as well as the Government, have much to contribute. Although the lead must come from the Government, both in the formulation of policy and the provision of the appropriate means-whether under the Lord President of the Council, or through the Advisory Council on Scientific Policy or the University Grants Committee-for seeing that expansion is kept in step, this report of the team under Dr. Dunsheath may well stimulate the closer association which is essential to the smooth implementation of policy.

\section{EDWARD JENNER, NATURALIST}

A Bio-Bibliography of Edward Jenner, 1749-1823 By W. R. LeFanu. Pp. $x x+176+29$ plates. (London: Harvey and Blythe, Ltd., 1951.) 84s.

T HE main concern of this volume is a bibliographical history of Jenner's medical discoveries. This has involved a voluminous correspondence and many tedious researches into bibliographical rarities and side-issues. All the relevant and avi ilable material has been faithfully and meticulously sifted by Mr. W. R. LeFanu, and he must be complimented on having in all human probability exhausted his subject. His work is, in fact, the first complete survey of all the editions and translations of the cow-pox inquiry of 1798 and also of the long series of Jenner's later explanatory memoirs, observations, instructions, propaganda and letters on vaccination. Richardson's belated and rather strange criticism of Jenner published in The Asclepiad of 1889 does not apparently come within the scope of the present work, which is unfortunate, as the author's opinion of it would have been illuminating.

But interesting and important as are the medical issues, many readers of the present review will turn preferably to Jenner's observations in the field of Nature. Here he owes acknowledgments to the stimulus and guidance of his mentor, John Hunter; but Jenner was himself so engrossed and ingenious a student of country life that he may well be regarded in his modest way as the Gilbert White of medicine. His merits as a naturalist have unfortunately been obscured by his discovery of vaccination.

Jenner's important observations on the cuckoo and the migration of birds have not been generally recognized. They are not mentioned by Eagle Clarke (1912), Mullens and Swan (1917) and Thomson (1926), and his memoirs are not represented in the catalogue of the great ornithological library of E. Ayer (1926). Indeed, Waterton (1838), Seebohm (1884) and Raspail (1925) flatly rejected Jenner's discoveries on the cuckoo, the last-mentioned author even dismissing them as an "absurd legend". On the other hand, ample confirmation came from Montagu (1802), Blackwall (1824), Macgillivray (1840), Newton (1893) and Jourdain (1925). Jenner, in fact, from his own observations of 1787, was the first to give a detailed and accurate account of the "murderous eviction" by the newly hatched cuckoo of the eggs and fledglings of the foster parents, and hence to become the sole object of their nurture and care. The statement, sometimes made, that this astonishing discovery is to be found in Aristotle is based on a misreading of the text. Jenner also found that young cuckoos are structurally modified to enable them to achieve this act of piracy. He was, however, disposed to minimize differences in size and markings between the eggs of the fosterer hedge-sparrow and cuckoo, whereas normally they are easily distinguishable in those respects, and also in the last resort, as he himself had found, by weight. This is not to gainsay the fact that the size of the cuckoo's egg has some relation to that of the fosterer, as Latter maintained in 1901, thus confirming Jenner. In the first draft of the cuckoo memoir Jenner had concluded that the eggs and nestlings of the fosterer were ejected by that bird herself ; but in $\mathbf{1 7 8 7}$ he had discovered his error, and therefore the correct version appears in the published paper of 1788.

Jenner's views on the migration of birds were pub. lished posthumously in 1824 . He was convinced of the reality of migration and of the stamina and urge necessary to undertake and complete it. The possibility of hibernation was scouted, and he carried out marking experiments which showed that birds returned to the same spot year after year. He believed that the cause of the migratory movements was the periodic efflorescence and subsequent shrinkage of the genital glands, in which view he may be deemed the precursor of the modern researches of Rowan.

In addition to his observations on the cuckoo and the migration of birds, Jenner carried out numerous investigations on hibernation and digestion in the hedgehog. It was in connexion with this work that Hunter addressed to Jenner his famous letter dated September 25, 1778, which Mr. LeFanu mentions but does not reproduce in full. Jenner also directed Hunter's attention to the difficult problem of the freemartin, and supplied the material on which Hunter based his memoir of 1767 on the bottle-nosed dolphin. The species was undoubtedly Tursiops tursio, and not the common dolphin Delphinus delphis as Hunter supposed.

The work has been handsomely printed and bound; but most of the illustrations would have been better reproduced as line blocks. The author is to be congratulated on the completion of this truly admirable bio-bibliography.

F. J. Cols

\section{THE SYNTHETIC APPROACH TO EVOLUTION}

Variation and Evolution in Plants

By G. Ledyard Stebbins, Jr. Pp. xx +643 . (London : Oxford University Press, 1950.) 50s. net.

GOR many years, the fountainhead of evolutionary thinking for botanists has been in California. Outstandingly prolific and versatile among the workers there has been Prof. G. L. Stebbins, and it is fitting that it is he who has produced this volume, in which he fully acknowledges the advice of many contemporaries. Only a sound and comprehensive book could be expected in such circumstances, and there can be no doubt that this is a work which will be used with gratitude by specialists as well as biologists in general for many years. The author's style is so lucid that this large book may be read through from cover to cover in relatively few sessions. Would that some other famous authors could keep simple facts so free from mystery!

The theme of the book is 'Neo-Darwinian'-"evolution has progressed chiefly by the accumulation of 